International Mathematical Forum, Vol. 9, 2014, no. 32, 1611 - 1614 HIKARI Ltd, www.m-hikari.com http://dx.doi.org/10.12988/imf.2014.48144

\title{
One More Mathematical Argument in Favor of Interdisciplinary Research and Diversity
}

\author{
L. Octavio Lerma ${ }^{1}$ and Olga Kosheleva ${ }^{2}$ \\ ${ }^{1}$ Computational Science Program \\ ${ }^{2}$ Department of Teacher Education \\ University of Texas at El Paso \\ $500 \mathrm{~W}$. University \\ El Paso, TX 79968, USA
}

Copyright (c) 2014 L. Octavio Lerma and Olga Kosheleva. This is an open access article distributed under the Creative Commons Attribution License, which permits unrestricted use, distribution, and reproduction in any medium, provided the original work is properly cited.

\begin{abstract}
In this paper, we show that mathematical results from the theory of deductive systems, results which have been used to explain the evolutionary advantage of sexual reproduction over asexual one, can be also used to explain potential advantages of interdisciplinary research and of diversity in the workplace.
\end{abstract}

Mathematics Subject Classification: 03B22, 91D99

Keywords: deductive systems, speed-up, interdisciplinary research

\section{Background}

A 1987 MIT book [6] by a renowned logician S. Yu. Maslov contains, among other things, a possible mathematical explanation of why sexual reproduction is more efficient than asexual. This explanation is based on the analysis of deductive systems.

When the environment changes, the original DNA - which was adequate for survival in the previous environment - is often no longer adequate. In this case, for the species to survive, they need to modify their DNA so as to make it more adequate for the changed environment. 
In general, there are main ways to change individual DNAs:

- via asexual reproduction, in which the parent's genes sequence pass to the offspring, usually with a mutation, and

- via sexual reproduction, in which the parents' genes are mixed (recombined) and a mutation is added to form the offspring's gene sequence.

The book [6] compares the smallest number of generations that are needed, for both ways, to achieve the desired change. The book proves a mathematical theorem, according to which, under some reasonable assumptions, the possibility of recombination makes the change exponentially faster.

This result explains the evolutionary advantage of sexual reproduction in precise mathematical terms.

Comment. The book [6] also gives an interesting explanation of why only two sexes are used and not three or four: namely, it proves that, in general, adding extra sexes will not speed up the process any further.

\section{Inter-Disciplinary Research vs. Research Within a Discipline}

\section{Idea.}

- When we work within a single discipline, it is more like mutations (while not necessarily a random one).

- On the other hand, inter-disciplinary research provides an opportunity to combine techniques and results from different disciplines.

In view of this analogy, the speed-up result from [6] explains the advantages of inter-disciplinary research.

Comment. Similar ideas appeared in [9].

\section{Diversity in Workplace}

Idea. A similar idea can explain the advantages of diversity in workplace, where:

- working within a single culture is similar to asexual reproduction, while

- diversity provides us with the possibility to productively combine several different cultural viewpoints. 
Thus, the main result from [6] explains potential drastic advantages of diversity.

Comment. Similar arguments explaining the benefits of diversity have also been described in $[1,2,3,4,5,7,8,10]$.

\section{Acknowledgments}

This work was supported in part by the National Science Foundation grant HRD-1242122 (Cyber-ShARE Center of Excellence).

\section{References}

[1] O. Castillo, P. Melin, E. Gamez, V. Kreinovich, and O. Kosheleva, "Intelligence Techniques Are Needed to Further Enhance the Advantage of Groups with Diversity in Problem Solving", Proceedings of the 2009 IEEE Workshop on Hybrid Intelligent Models and Applications HIMA'2009, Nashville, Tennessee, March 30 - April 2, 2009, pp. 48-55.

[2] L. Hong and S. E. Page, "Problem solving by heterogeneous agents", Journal of Economic Theory, 2001, Vol. 97, No. 1, pp. 123-163.

[3] L. Hong and S. E. Page, "Groups of diverse problem solvers can outperform groups of high-ability problem solvers", Proceedings of the National Academy of Sciences, 2004, Vol. 101, No. 46. pp. 16385-16389.

[4] O. Kosheleva, "Diversity is the Optimal Education Strategy: A Mathematical Proof", International Journal of Innovative Management, Information $\&$ Production (IJIMIP), 2013, Vol. 4, No. 1, pp. 1-8.

[5] C. C. Kuo, F. Glover, and K. S. Dhir, "Analyzing and modeling the maximum diversity problem by zero-one programming", Decision Sciences, 1993, Vol. 24, No. 6, pp. 1171-1185.

[6] S. Yu. Maslov, Theory of Deductive Systems and Its Applications, MIT Press, Cambridge, Massachusetts, 1987.

[7] J. H. Miller and S. E. Page, Complex Adaptive Social Systems: The Interest in Between, Princeton University Press, Princeton, New Jersey, 2006.

[8] S. E. Page, The Difference: How the Power of Diversity Creates Better Groups, Firms, Schools, and Societies, Princeton University Press, Princeton, New Jersey, 2007. 
[9] P. Pinheiro da Silva, A. Velasco, O. Kosheleva, and V. Kreinovich, "How AI-Type Uncertainty Ideas Can Improve Inter-Disciplinary Collaboration and Education: Lessons from a Case Study", Journal of Advanced Computational Intelligence and Intelligent Informatics JACIII, 2010, Vol. 14, No. 6, pp. 700-707.

[10] K. Suriya, T. Sudtasan, T. Wang, O. Lerma, and V. Kreinovich, "Diversity Is Beneficial for a Research Group: One More Quantitative Argument", Journal of Uncertain Systems, to appear.

Received: August 10, 2014; Published: October 29, 2014 